\title{
A Comparative Evaluation between Propolis and Mineral Trioxide Aggregate as Pulpotomy Medicaments in Primary Molars
}

\author{
Kavita Madan¹, Sudhindra Baliga², Pranjali Deulkar³, Nilima Thosar4, \\ Nilesh Rathi ${ }^{5}$, Meghana Deshpande ${ }^{6}$, Sphurti Bane ${ }^{7}$
}

\begin{abstract}
1Department of Paediatrics and Preventive Dentistry, Sharad Pawar Dental Collegeand and Hospital, Datta Meghe Institute of Medical Sciences (Demeed to be University), Sawangi (M), Wardha, Maharashtra, India. ${ }^{2}$ Department of Paediatrics and Preventive Dentistry, Sharad Pawar Dental College and Hospital, Datta Meghe Institute of Medical Sciences (Demeed to be University), Sawangi (M), Wardha, Maharashtra, India. ${ }^{3}$ Department of Paediatrics and Preventive Dentistry, Sharad Pawar Dental Collegeand and Hospital, Datta Meghe Institute of Medical Sciences (Demeed to be University), Sawangi (M), Wardha, Maharashtra, India. ${ }^{4}$ Department of Paediatrics and Preventive Dentistry, Sharad Pawar Dental College and and Hospital, Datta Meghe Institute of Medical Sciences (Demeed to be University), Sawangi (M), Wardha, Maharashtra, India. ${ }^{5}$ Department of Paediatrics and Preventive Dentistry, Sharad Pawar Dental College and and Hospital, Datta Meghe Institute of Medical Sciences (Demeed to be University), Sawangi (M), Wardha, Maharashtra, India. ${ }^{6}$ Department of Paediatrics and Preventive Dentistry, Sharad Pawar Dental College and and Hospital, Datta Meghe Institute of Medical Sciences (Demeed to be University), Sawangi (M), Wardha, Maharashtra, India. ${ }^{7}$ Department of Paediatrics and Preventive Dentistry, Sharad Pawar Dental College and and Hospital, Datta Meghe Institute of Medical Sciences (Demeed to be University), Sawangi (M), Wardha, Maharashtra, India.
\end{abstract}

\section{ABSTRACT}

\section{BACKGROUND}

Pulpotomy is defined as the complete removal of coronal portion of dental pulp followed by placement of a suitable dressing or medicament that will promote healing and preserve the vitality of the tooth. ${ }^{1}$ This treatment helps to maintain the primary tooth in the arch and to fulfil its function in primary and mixed dentition period. ${ }^{2}$ Since its introduction by Sweet (1932), Formocresol (FC) has been a popular pulpotomy medicament in the primary dentition for the past 80 years. $^{3}$ However, it has many disadvantages like cytotoxicity, pulpal inflammation and necrosis, systemic disturbances, mutagenic and carcinogenic potential and immunologic responses. 4

\section{METHODS}

40 carious primary molars selected from 32 children aged between 4-9 years were included in the study. The selected teeth were randomly divided into 2 groups. Group A: 20 primary molars to be pulpotomised with MTA. Group B: 20 primary molars were treated with $15 \%$ Propolis tincture. The children were recalled at 3, 6and 12-months interval for clinical and radiographical evaluation.

\section{RESULTS}

There was also absence of periapical radiolucency in propolis group at 3 months whereas in the MTA group periapical radiolucency was present in $1(5.6 \%)$ tooth at 3 months. There was absence of sinus/ fistula in MTA group, while one (5.9\%) tooth developed sinus/ fistula in propolis group at 6 months. There was also absence of sinus/ fistula in MTA group, while two (11.1\%) teeth developed sinus/ fistula in propolis group at 12 months. At 12 months success rate was higher in MTA group (6 months- $100 \%$ and 12 months $-94.4 \%$ ) as compared to Propolis (6 months- $88.2 \%$ and 12 months - 88.9\%).

\section{CONCLUSIONS}

Clinical outcome of Propolis is comparable to that of MTA at both 6 and 12 months follow up period. Hence, Propolis seems to be a promising and a reliable medicament for pulpotomy.

\section{KEY WORDS}

Pulpotomy, MTA, Propolis, Primary Teeth
Corresponding Author:

Dr. Pranjali Deulkar,

Department of Pediatric and Preventive Dentistry, Sharad Pawar Dental College, Datta Meghe Institute of Medical Sciences, Sawangi (M), Wardha-442001,

Maharashtra, India.

E-mail: pranjali.deulkar@gmail.com

DOI: $10.14260 / \mathrm{jemds} / 2020 / 273$

Financial or Other Competing Interests: None.

How to Cite This Article:

Madan K, Baliga S, Deulkar P, et al. A comparative evaluation between propolis and mineral trioxide aggregate as pulpotomy medicaments in primary molars. J. Evolution Med. Dent. Sci. 2020;9(15):1256-1260, 10.14260/jemds/2020/273

Submission 27-11-2019, Peer Review 21-03-2020, Acceptance 27-03-2020, Published 13-04-2020.

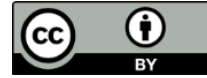




\section{BACKGROUND}

These drawbacks of formocresol have led to the use of alternate medicaments for pulpotomy in primary teeth. Many different alternative techniques including electrosurgery ${ }^{5}$ and use of lasers ${ }^{6}$ have been proposed while medicaments such as glutaraldehyde, ${ }^{7}$ ferric sulfate, ${ }^{8}$ enriched collagen solution, ${ }^{9}$ MTA $^{4}$ and Propolis ${ }^{10}$ have also been explored. In 1993, Mineral Trioxide Aggregate (MTA) was developed and was introduced by Loma Linda University, California, USA as a root-end filling material. The indications for using MTA mainly include the formation of root end barrier in immature permanent teeth, thereby permitting proper apical seal and repairing the furcal perforations. MTA has proven itself to be one of the most versatile materials in the field of dentistry due to its excellent long-term prognosis and relative ease of its application. ${ }^{11}$

Propolis, a resinous substance produced from plant buds by honeybees is a traditional medicine known for its claimed beneficial effects on human health. It stands out for its numerous pharmaceutical properties like anti-inflammatory, anti-bacterial, antioxidant, antitumor, antifungal, antiviral and immunomodulating properties. ${ }^{12,13}$ In dentistry, propolis has found a wide variety of applications as an intracanal medicament, 14 root canal irrigant, 15 for wound healing, storage of avulsed teeth, as an antiplaque agent, in the treatment of periodontitis, dentinal hypersensitivity and denture stomatitis. ${ }^{16}$ Exploring its diverse applications in dentistry, it is of great interest to determine the reliability and efficacy of propolis as a medicament in pulp therapy procedures. Hence, the aim of the present study was to assess the success rate of propolis and MTA as a pulpotomy medicament in primary molars.

We wanted to assess the success rate of Propolis and MTA as pulpotomy medicament in primary molars.

\section{METHODS}

This study was carried out on 40 carious primary molars selected from 32 children aged between 4-9 years. A double blind clinical trial was conducted to evaluate and compare the clinical and radiographic success of pulpotomy of primary molars performed with MTA and Propolis. The participating children and their parents were informed about the protocol of the study and prior parental consent was obtained. Ethical clearance to conduct the study was obtained from the institution.

Primary molars selected in this study were based on clinical and radiographical screening. Healthy patient between 4-9 yrs. of age with cariously exposed primary molars which could be restored and history of spontaneous pain were included in the study. The patients with draining sinus, pathological mobility, history of persistent tooth ache were excluded from the study. Periapical radiolucency, dystrophic calcifications, interradicular bone loss and exfoliating teeth were not selected for the study.

For each of the selected tooth, topical anaesthesia was applied. Subjective and objective symptoms for successful effectiveness anaesthesia were assessed. After achieving it, isolation was obtained using rubber dam application. All the peripheral infected caries was removed and pulp chamber was then deroofed using carbide bur followed by irrigation to remove dentinal debris. Coronal pulp amputation was achieved with small and medium slow-speed round burs (sterile), thereby taking adequate care to avoid cutting the pulp chamber floor. The remaining pulp tissue was excavated with sterile spoon excavators and the chamber was irrigated with saline. Haemorrhage was controlled by applying pressure with wet sterile cotton pellets. On achieving haemostasis, the radicular pulp was assessed, and tooth was considered for pulpotomy only if bleeding was arrested naturally.

The selected teeth were randomly divided into 2 groups. Group A had 20 primary molars for MTA pulpotomy. Group B had 20 primary molars for $15 \%$ Propolis tincture pulpotomy. For randomization simple random sampling by Lottery Method was done.

\section{Selection of Subjects}

Study was carried out on 40 carious primary molars selected from 32 children aged between 4-9 years. A double-blind clinical trial was conducted to evaluate and compare the clinical and radiographic success of pulpotomy of primary molars performed with MTA and Propolis. The participating children and their parents were informed about the protocol of the study and parental consent was obtained.

Ethical clearance to conduct the study was obtained from the institution. Primary molars selected in this study were based on clinical and radiographical screening.

\section{Inclusion Criteria}

- Healthy patient between 4-9 years of age.

- Cariously exposed primary molars.

- History of spontaneous pain.

- Restorable tooth.

\section{Exclusion Criteria}

- Patient with draining sinus.

- Pathological mobility.

- History of unprovoked tooth ache/persistent tooth ache.

- Highly viscous, sluggish, absent haemorrhage observed at radicular.

\section{Radiographic Screening Inclusion Criteria}

- At least two-third of remaining root length.

Exclusion Criteria

- Periapical radiolucency.

- Dystrophic calcification.

- Interradicular bone loss.

- Exfoliating tooth.

\section{Mineral Trioxide Aggregate Group}

After complete removal of the coronal pulp and obtaining the haemostasis, the MTA paste was obtained by mixing 3 parts 
of powder with 1 part of water to obtain a putty like consistency. This mix was then carried with the MTA carrier and placed in the pulp chamber and condensed lightly with a moistened cotton pellet. This was followed by placement of a layer of zinc oxide eugenol (ZOE) thick mix. In the next appointment, temporary dressing of ZOE was replaced with glass ionomer cement.

\section{Propolis Group}

After haemostasis was obtained, a cotton pellet was first dampened with 15\% Propolis tincture and placed on the amputated pulp stumps till a brownish to black discoloration of fixed radicular pulpal tissue was seen on the orifice. A zinc oxide eugenol cement layer was placed to seal the coronal pulp chamber and later restored with glass ionomer cement.

In both the groups following pulpotomy, a pre-formed stainless-steel crown was placed; occlusal contacts were checked and adjusted where necessary. Postoperative intraoral periapical radiograph was taken. The children were recalled at 3, 6- and 12-months interval for clinical and radiographical evaluation. The postoperative clinical and radiographic success was evaluated by the criteria enumerated in table 1.

\begin{tabular}{|cc|}
\hline Clinical & Radiographical \\
Pain on percussion & Periapical radiolucency \\
Presence of sinus tract & Furcal radiolucency \\
Mobility & Root resorption \\
Table 1. Evaluation Criteria for Postoperative & Damage to succedaneous tooth follicle \\
Clinical and Radiographic Success \\
\hline
\end{tabular}

\section{Statistical Analysis}

Statistical analysis for the comparison of MTA and Propolis as a pulpotomy medicament in primary molars was carried out to find the significant difference between two groups. The statistical test used for the analysis of the result was Chi Square test

\section{Chi Square Test}

Several proportions can be compared using a 2 by chi-square test. For example, a random sample of people can be sub divided into $\mathrm{k}$ age groups and counts made of those individuals with and those without a particular attribute. For this sample, a 2 by chi-square test could be used to test whether or not age has a statistically significant effect on the attribute studied. This is a test of the independence of the row and column variables; it is equivalent to the chi-square independence tests for 2 by 2 and by c chi-square tables.

$(x)^{2}=\sum_{i=1}^{r} \sum_{j=1}^{c} \frac{(0 i j-E i j)^{2}}{E i j}$

Where, for $r$ rows and c columns of $n$ observations, $\mathrm{O}$ is an observed frequency and $\mathrm{E}$ is an estimated expected frequency. The expected frequency for any cell is estimated as the row total times the column total then divided by the grand total.

Forty teeth from 32 children were randomly divided into two groups and treated with MTA and Propolis. At 3 months, of the 32 children, three children with five pulpotomised teeth (two teeth from the MTA and three from Propolis group) dropped out of the study after the pulpotomy was performed as one of the subjects changed his hometown and two did not report even after contacting them. Thus, 35 treated teeth were evaluated at 3 months. At 6 months, one child with two treated from MTA group dropped out of the study due to lack of parents of cooperation. A total of 28 children with 33 teeth were assessed at 6 months. While at the 12 months follow up, 2 children (one from MTA and one from Propolis) who remained absent for 3- and 6-months follow-up reported back at 12 months. Thus, 36 treated teeth were evaluated at 12 months.

\section{RESULTS}

There was no pain, sinus or fistula and pathological tooth mobility in both the groups at 3 months. There was also absence of periapical radiolucency in propolis group at 3 months whereas in the MTA group periapical radiolucency was present in $1(5.6 \%)$ tooth at 3 months. This difference in periapical radiolucency between the groups was not statistically significant at 3 months $(p>0.05)$. There was absence of sinus/fistula in MTA group, while one (5.9\%) tooth developed sinus/ fistula in propolis group at 6 months, but the difference was not significant. There was also absence of sinus/fistula in MTA group, while two (11.1\%) teeth developed sinus/fistula in propolis group at 12 months which was statistically not significant.

\begin{tabular}{|cccccc|}
\hline \multicolumn{7}{c}{ MTA } & Propolis & Chi-Square Value & P Value \\
3 & Success & $17(94.4 \%)$ & $17(100 \%)$ & & \\
Months & Failure & $1(5.6 \%)$ & $0(0 \%)$ & 0.97 & 0.51 \\
6 & Success & $16(10 \%)$ & $15(88.2 \%)$ & & 0.25 \\
Months & Failure & $0(0 \%)$ & $2(11.8 \%)$ & 2.00 & 0.50 \\
12 & Success & $17(94.4 \%)$ & $16(88.9 \%)$ & 0.36 & $0.1 \%)$ \\
Months & Failure & $1(5.6 \%)$ & $2(11.1 \%)$ & \\
\hline \multicolumn{7}{c}{ Table 2. Success Rate of MTA and Propolis Pulpotomy } \\
in Primary Molars at 3, 6, and 12 Months
\end{tabular}

\begin{tabular}{|c|c|c|c|c|c|}
\hline Parameter & & MTA & PROPOLIS & $\begin{array}{c}\text { Chi-Square } \\
\text { Value }\end{array}$ & P Value \\
\hline Pain & $\begin{array}{l}\text { Absent } \\
\text { Present }\end{array}$ & $\begin{array}{c}16(100 \%) \\
0(0 \%)\end{array}$ & $\begin{array}{c}17(100 \%) \\
0(0 \%)\end{array}$ & one & - \\
\hline Sinus/Fistula & $\begin{array}{l}\text { Absent } \\
\text { Present }\end{array}$ & $\begin{array}{c}16(100 \%) \\
0(0 \%)\end{array}$ & $\begin{array}{c}16(94.1 \%) \\
1(5.9 \%)\end{array}$ & 0.97 & 0.51 \\
\hline $\begin{array}{l}\text { Pathological } \\
\text { Mobility }\end{array}$ & $\begin{array}{c}\text { Absent } \\
\text { Present } \\
\text { Total }\end{array}$ & $\begin{array}{c}16(100 \%) \\
0(0 \%) \\
16(\mathbf{1 0 0 \% )}\end{array}$ & $\begin{array}{c}17(100 \%) \\
0(0 \%) \\
17(\mathbf{1 0 0 \% )}\end{array}$ & - & - \\
\hline & ITA and & opolis Pl & $\begin{array}{l}\text { cal Parame } \\
\text { otomy at } 6\end{array}$ & $\begin{array}{l}\text { ters betwee } \\
\text { Months }\end{array}$ & \\
\hline
\end{tabular}

\begin{tabular}{|c|c|c|c|c|c|}
\hline Parameter & & MTA & Propolis & Chi-Square Value & P Value \\
\hline $\begin{array}{c}\text { PA } \\
\text { Radiolucency }\end{array}$ & $\begin{array}{l}\text { Absent } \\
\text { Present }\end{array}$ & $\begin{array}{c}17(94.4 \%) \\
1(5.6 \%)\end{array}$ & $\begin{array}{c}17(94.4 \%) \\
1(5.6 \%)\end{array}$ & 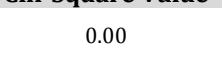 & 1.0 \\
\hline $\begin{array}{c}\text { Furcal } \\
\text { Radiolucency }\end{array}$ & $\begin{array}{l}\text { Absent } \\
\text { Present }\end{array}$ & $\begin{array}{c}18(100 \%) \\
0(0 \%)\end{array}$ & $\begin{array}{c}16(88.9 \%) \\
2(11.1 \%)\end{array}$ & 2.11 & 0.14 \\
\hline $\begin{array}{l}\text { Root } \\
\text { resorption }\end{array}$ & $\begin{array}{l}\text { Absent } \\
\text { Present }\end{array}$ & $\begin{array}{c}18(100 \%) \\
0(0 \%)\end{array}$ & $\begin{array}{c}18(100 \%) \\
0(0 \%)\end{array}$ & - & - \\
\hline $\begin{array}{l}\text { Damage to } \\
\text { succedaneous } \\
\text { tooth follicle }\end{array}$ & $\begin{array}{c}\text { Absent } \\
\text { Present } \\
\text { Total } \\
\end{array}$ & $\begin{array}{c}18(100 \%) \\
0(0 \%) \\
18(\mathbf{1 0 0 \% )}\end{array}$ & $\begin{array}{c}18(100 \%) \\
0(0 \%) \\
18(\mathbf{1 0 0 \% )}\end{array}$ & & \\
\hline & $\begin{array}{l}\text { le } 4 . C \\
\text { eeen } M\end{array}$ & $\begin{array}{l}\text { mparison } \\
A \text { and Prol }\end{array}$ & $\begin{array}{l}\text { of Radiogr } \\
\text { polis Pulpo }\end{array}$ & $\begin{array}{l}\text { aphic Parameters } \\
\text { tomy at } 12 \text { Months }\end{array}$ & \\
\hline
\end{tabular}




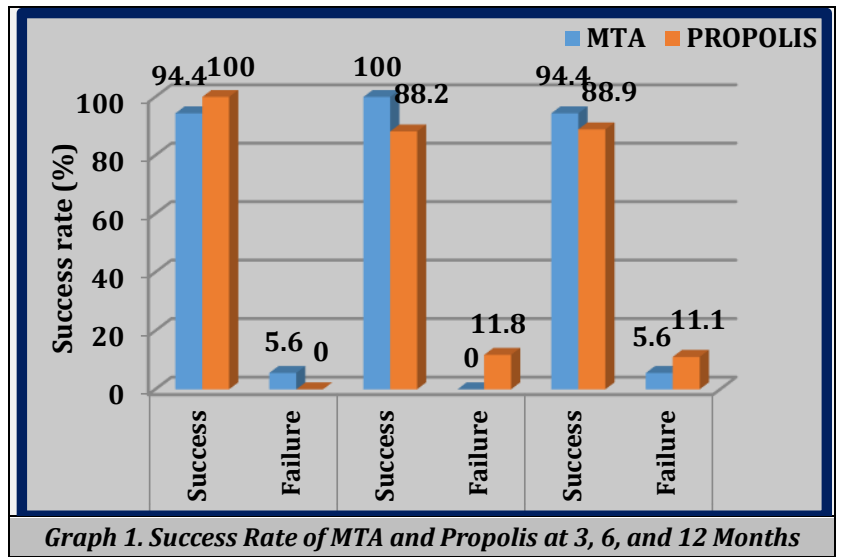

Only one tooth developed periapical radiolucency (5.6\%) in propolis group at 12 months while none of the teeth in the MTA group developed periapical radiolucency at 12 months. This difference in periapical radiolucency between the groups was not statistically significant at 12 months ( $p>0.05)$. There was also absence of furcal radiolucency in MTA group, while two $(11.1 \%)$ teeth developed furcal radiolucency in propolis group at 12 months. There was no statistically significant difference in presence of furcal radiolucency between MTA and propolis group at 12 months ( $p>0.05)$. At 3 months, overall success rate in MTA group (94.4\%) was found to be lower as compared to propolis group (100\%). While at 6 and 12 months, success rate was higher in MTA group (6 months$100 \%$ and 12 months $-94.4 \%$ ) as compared to propolis (6 months- $88.2 \%$ and 12 months - 88.9\%).

\section{DISCUSSION}

The objective of pulp therapy in a child patient is to maintain the tooth in a healthy condition so that the tooth is able to fulfil its role as a useful component in both primary as well as young permanent dentition. An ideal material used as a pulpotomy medicament should be able to protect the remaining pulp tissue. It should not only be bactericidal but also should be biocompatible with pulpal tissues and adjoining structures. It should not interfere with physiological root resorption but should be able to promote a tissue repair process. ${ }^{14}$

In recent times, with the introduction of new materials, which are not only biocompatible but are bioinductive, the emphasis for the selection of the material is from mere preservation to regeneration. Mineral trioxide aggregate is one such material which has been used in regenerative pulpotomy. ${ }^{15}$ It provides good sealing ability thereby minimizing the infiltration of bacteria, toxins and stains. ${ }^{16}$

Propolis is a sticky, resinous substance collected by honey bees from the leaves, buds and sap of plants, and then mixed with secreted bee wax and is composed of resins (40-55\%), bee wax and fatty acids (20-35\%), aromatic oils (about $10 \%$ ), pollen (about 5\%), and other components like minerals and vitamins. It is known to have an antibacterial, antifungal, antiviral, antitumor and immunomodulating properties. Caffeic Acid Phenethyl Ester (CAPE) a potent antioxidant \& anti-inflammatory agent is an important substance present in propolis. ${ }^{17}$ Owing to the properties, the present study evaluated the efficacy of $15 \%$ Propolis tincture as a pulpotomy medicament.

Postoperative clinical evaluation of the two groups in the present study included pain, mobility and sinus/fistula. The results of this study showed a non-significantly higher clinical success rate of $94.4 \%$ in MTA group as compared to $88.9 \%$ success rate in Propolis group at the end of 12 months (Table 2). This was in accordance with the study conducted by Holan G et al who showed $97 \%$ of success rate with MTA. ${ }^{18}$ However, the study conducted by Godhi B et al found $100 \%$ clinical success rate at the end of 12 months when MTA was used as a pulpotomy medicament. The clinical success rate of MTA could be attributed to the capacity of MTA to stimulate the formation of dental tissues thereby leading to formation of hard dentinal bridge. ${ }^{19}$

The clinical success for Propolis could be attributed to its anti-inflammatory and antimicrobial property. It forms hard tissue bridge by stimulation of various enzyme systems, cell metabolism, circulation and collagen formation. These effects could be attributed to the presence of vitamin $C$, arginine, provitamin A, B complex and minerals such as copper, iron, zinc and bioflavonoids. It breaks down bacterial cell wall, cytoplasm and prevents bacterial cell division. In the present study, the clinical success rate for Propolis was $88.9 \%$ (Table 2). The results were in accordance with the study conducted by Bharti $\mathrm{K}$ et al where the success rate of about $84 \%$ was obtained. ${ }^{20}$ However, Alafandy AS et al also found a success rate of $87.23 \%$ in his study. ${ }^{21}$

The present study showed that there was absence of pain, mobility and pathologic tooth mobility in both the groups at 6 months. There was absence of sinus or fistula in MTA group. This could be attributed to the fact that MTA has a good sealing ability and therefore they are capable of inducing hard-tissue formation in pulpal tissue, and thereby reducing the microleakage. ${ }^{22}$ One (5.9\%) tooth developed sinus/ fistula in Propolis group at 6 months. However, in the literature, direct evidence of sealing property of Propolis is not evidenced. It is reported that Propolis helps in collagen synthesis and assists in wound healing. The role of final restoration over pulpotomized primary molars therefore becomes significant in preventing microleakage. Fracture of the glass ionomer restoration at the recall visit could have been the reason for microleakage and failure of pulpotomy. The reason for pulpotomy failures in primary teeth with caries exposure could also be attributed to misdiagnosis of inflammation present in the radicular pulp before initiating treatment and/or pulp contamination due to microleakage of large multi-surface amalgam rather than stainless steel crowns. ${ }^{23}$

In the present study, there was absence of furcal radiolucency, root resorption, pathology and damage to underlying tooth at 3 months in both the groups. Periapical radiolucency was absent in Propolis group at 3 months whereas in the MTA group periapical radiolucency was present in 1 tooth. As there is lack of studies with respect to Propolis being used as a pulp capping and a pulpotomy agent, no clear evidence/reasoning has been published about the occurrence of periapical and furcal radiolucency in relation to Propolis. In a study conducted by Carmen V et al. evaluating the effectiveness of Propolis tincture, they concluded that Propolis tincture was an effective pulpotomy medicament. ${ }^{19}$ The failure for MTA group could be attributed to the fact that 
as MTA has the ability of cytokine release which could be responsible for the changes in the response of the pericoronal osteocytes to the released cytokines, especially in comparison to osteocytes present in other locations which might be a cause responsible for the development of radiolucency. Function of cytokines ultimately depends upon which type of receptors is present in the tissue. It can be postulated that dental follicles may also affect these receptors. The results were in accordance with the study performed by Neamatollahi $\mathrm{H}$ et al who showed lowest radiographic success rates of about $69.2 \%$ after one year. ${ }^{24}$

\section{CONCLUSIONS}

Clinically, at 12 months, the success rate for MTA was $100 \%$, while $88.9 \%$ success was achieved from Propolis group. Radiographically, at 12 months, MTA group showed $94.4 \%$ of overall success while 88.9 \% success was obtained from Propolis group. There was no significant difference in overall success between the two groups at 3, 6 and 12 months $(p>0.05)$. Propolis seems to be a promising and a reliable medicament for pulpotomy.

\section{REFERENCES}

[1] Lewis TM, Law DB, Finn SB. Pulp treatment of primary teeth. Textbook of Clinical Pedodontics. $4^{\text {th }}$ edn. Philadelphia: W B Saunders Company 2001.

[2] Fuks AB. Current concepts in vital primary pulp therapy. European Journal of Paediatric Dentistry 2002;3(3):11520.

[3] Fuks AB. Vital pulp therapy with new materials for primary teeth: new directions and treatment perspectives. Journal of Endodontics 2008;34(Suppl 7):S18-S24.

[4] Agamy HA, Bakry NS, Mounir MF, et al. Comparison of mineral trioxide aggregate and formocresol as pulp capping agents in pulpotomized primary teeth. Pediatric Dentistry 2004;26(4):302-9.

[5] Dean JA, Mack RB, Fulkerson BT, et al. Comparison of electrosurgical and formocresol pulpotomy procedures in children. International Journal of Paediatric Dentistry 2002;12(3):177-82.

[6] Liu JF, Chen LR, Chao SY. Laser pulpotomy of primary teeth. American Academy of Pediatric Dentistry 1999;21(2):128-9.

[7] Sun HW, Feigal RJ, Messer HH. Cytotoxicity of glutaraldehyde and formaldehyde in relation to time of exposure and concentration. American Academy of Pediatric Dentistry 1990;12(5):303-7.

[8] Cortes O, Boj JR, Canalda C, et al. Pulpal tissue reaction to formocresol vs. ferric sulfate in pulpotomized rat teeth. Journal of Clinical Pediatric Dentistry 1997;21(3):24753.
[9] Llewelyn DR. UK National Clinical Guidelines in Paediatric Dentistry. The pulp treatment of the primary dentition. International Journal of Paediatric Dentistry 2000;10(3):248-52.

[10] Del Valkyrie C, Rodriguez G, Carpio MH, et al. Pulpotomy in primary molar pulp with tincture of propolis $10 \%$. Revista Cubana de Estomatolologia 2007;44(3):109-12.

[11] Naik S, Hegde AH. Mineral trioxide aggregate as a pulpotomy agent in primary molars: an in vivo study. Journal of the Indian Society of Pedodontics and Preventive Dentistry 2005;23(1):13-6.

[12] Hu F, Hepburn HR, Li Y, et al. Effects of ethanol and water extracts of propolis (Bee glue) on acute inflammatory animal models. Journal of Ethnopharmacology 2005;100(3):276-83.

[13] Ahuja V, Ahuja A. Apitherapy - a sweet approach to dental diseases. Part II: Propolis. Journal of Academy of Advanced Dental Research 2011;2(2):1-7.

[14] Esmeraldo MRA, De Carvalho MGF, De Carvalho RA, et al. Inflammatory effect of green propolis on dental pulp in rats. Brazilian Oral Research 2013;27(5):417-22.

[15] Praveen K, Rashmi N, Vipin B, et al. Pulpotomy medicaments: continued search for new alternatives- a review. Journal of Oral Health and Dental Management 2014;13(4):883-90.

[16] Simancas-Pallares MA, Díaz-Caballero AJ, Luna-Ricardo LM. Mineral trioxide aggregate in primary tooth pulpotomy. A systematic literature review. Medicina Oral Patologia Oral y Cirugia Bucal 2010;15(6):e942-6.

[17] Madan KA, Khatri S, Baliga MS. "Propolis"- a promising medicament in dentistry. Arch of Dent and Med Res 2016;2(5):13-6

[18] Holan G, Eidelman E, Fuks AB. Long-term evaluation of pulpotomy in primary molars using mineral trioxide aggregate or formocresol. Pediatric Dentistry 2005;27(2):129-36.

[19] Carmen V. Pulpotomy in primary molar pulp with tincture of propolis 10\%. Revista Cubana de Estomatologia 2007;44(3):125-30.

[20] Bharti K, Kumar R, Khanna R. Clinical and radiographical evaluation of mineral trioxide aggregate, biodentine and propolis as pulpotomy medicaments in primary teeth. Journal of Restorative Dentistry and Endodontics 2015;40(4):276-85.

[21] Alafandy AS, Barakat SS. Histological evaluation of pulp response to Syrian crude propolis as a pulpotomy agent in primary and immature permanent teeth - In vivo study. Quintessence International 2015;9(3):201-09.

[22] Furze HA, Furze ME. Pulpotomy with laser in primary and young permanent teeth. The Journal of Oral Laser Applications 2006;6(1):53-8.

[23] Fei AL, Udin RD, Johnson R. A clinical study of ferric sulfate as a pulpotomy agent in primary teeth. Pediatric Dentistry 1991;13(6):327-32.

[24] Neamatollahi H, Tajik A. Comparison of clinical and radiographic success rates of pulpotomy in primary molars using Formocresol, Ferric Sulfate and MTA. Journal of Dentistry 2006;3(1):7-14. 